\title{
A systematic review and quality assessment of therapeutic group process questionnaires
}

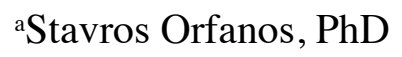

${ }^{\mathrm{b}}$ Erin Burn, MSc

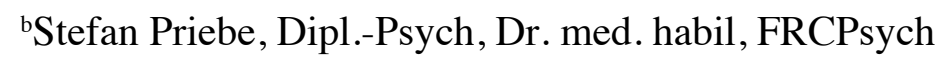

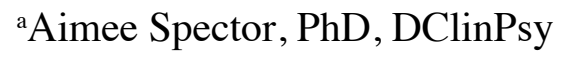

${ }^{a}$ University College London, Clinical, Education and Health Psychology, Division of

Psychology and Language Sciences, London, United Kindgom

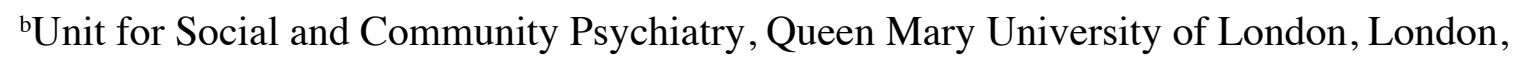
United Kingdom

*Requests for reprints should be addressed to Stavros Orfanos, University College London, Clinical, Education and Health Psychology, Division of Psychology and Language Sciences, 1-19 Torrington Place, London, United Kindgom, WC1E 7HB, stavros.orfanos.16@ucl.ac.uk 


\begin{abstract}
The aims of this study were to systematically review the literature on questionnairebased group process measures and assess the psychometric scale development properties of these measures. A systematic search of questionnaire-based measures of group process was conducted from four databases: PsycINFO, Medline, EMBASE and AMED. A quality assessment was undertaken using established criteria. Only studies that described the development of questionnaire-based scales were included. Seventeen studies which described thirteen measures were included in the analysis. The developed list highlights a range of questionnaires that can be used by clinicians and researchers seeking to measure either 'specific therapeutic group mechanisms' or 'overall group experiences'. Further research should focus on developing the content validity of these scales by involving the target population during item selection and reduction.
\end{abstract}

Keywords: Group therapy, group process, measures, psychometric assessment, questionnaire 
A Systematic Review and Quality Assessment of Therapeutic Group Process Questionnaires Psychological therapies are often delivered in groups involving two or more individuals. Due to increasing demands for inexpensive and accessible therapies (McCrone, 2008), groups are becoming an increasingly common approach in community and acute inpatient mental health settings (Burlingame, 2014; Lo Coco et al., 2019). In addition to the pragmatic benefits of groups, factors inherent to a group environment are also valued on a clinical level, where social aspects of the group setting are utilised as an agent of clinical change (Lo Coco et al., 2015). The mechanisms of therapeutic change inherent to the interaction between group members in group therapies are broadly described as 'group processes' (Garcia-Cabeza et al., 2011).

Burlingame and colleagues (2013) developed an organisational framework to conceptualise the role of group processes in small group treatments. In their model of group therapies, they distinguished between the group form (structure) and group function (processes). Burlingame and colleagues refer to group form as actions imposed on a group by the leader which influences the structure of the group, including the selection of group members and the composition of the group. Group processes, on the other hand, are considered as primary mechanisms of change associated with interactions between members. More specifically, Burlingame and colleagues (2013) highlight five components of 'emergent' processes describing member/leader interactions (including interpersonal feedback and self-disclosure, leader interventions) or by products of interactions (including cohesion and therapeutic factors) within their model. They also highlight the role of social psychological processes from organisational psychology principles that impact groups, including conformity, power, and management of conflict.

The measurement of group processes has important implications for both researchers and clinicians interested in monitoring and/or evaluating interactions between people in a 
therapeutic group setting (Delucia-Waack, 1997; Jensen et al., 2012). In terms of research, the Medical Research Council Framework (Campbell et al., 2007) guidance recommends that randomised controlled trials (RCTs) of complex interventions map mechanisms of change linked to desired outcomes. RCTs of group therapies are therefore increasingly seeking to measure unaccounted outcome variance related to group processes in addition to theoryspecific mechanisms common to individual therapy (for example, cognitive restructuring) (Priebe et al., 2013). In terms of clinical practice, therapists delivering routine therapy groups are encouraged to monitor group processes for their own audit and/or evaluative purposes (Marmarosh, 2018). This is in accordance with the literature highlighting the relationship between group processes and therapeutic outcomes (Chapman et al., 2012). A number of meta-analyses have concluded that group processes can be identified independently from the method-specific tasks implemented (Burlingame et al., 2004; Burlingame et al., 2013). However, despite the importance of measuring group processes, selecting an appropriate measure of group process is widely recognised as a challenging task (Thayer \& Burlingame, 2014).

Within the group therapy literature, two broad categories of group process measures exist. The first category of measures are questionnaire-based tools that seek to measure group processes as phenomena, where "some aspect or characteristic of the member, leader or group behaviour" are described (Fuhriman \& Burlingame, 1994b, p. 503). In doing so, the degree or intensity to which pre-defined group mechanisms are present or experienced is rated, typically on a Likert-type scale. Questionnaire-based measures of group phenomena are quick, inexpensive, and easy to use (Burlingame et al., 2006). They can either be selfreported, rated by the group leader, or rated by an independent observer. They can be used across multiple group sessions to either regularly track the progress of therapy or explore how group processes develop over time (Bakali et al., 2013). 
Yalom's theoretical contributions on curative, or helpful, group factors have been highly influential within the field of group phenomena research, (Yalom \& Leszcz, 2005; Yalom, 1985). Yalom described eleven beneficial mechanisms of change associated with clinical outcomes including: universality, altruism, instillation of hope, imparting information, corrective recapitulation of primary family experience, development of socialising techniques, imitative behaviour, cohesiveness, existential factors, catharsis, interpersonal learning-input, interpersonal learning-output/input, and self-understanding (Yalom \& Leszcz, 2005). Measures developed to assess Yalom's therapeutic curative factors include the Therapeutic Factor Inventory (TFI) (Lese \& MacNair-Semands, 2000) and TFIShort (TFI-S) (MacNair-Semands, Ogrodniczuk, \& Joyce, 2010). MacKenzie's construct of group climate (MacKenzie, 1983) is also a commonly assessed group process phenomena (Johnson et al., 2006) measured by the Group Climate Questionnaire. Unlike Yalom's curative factors, which describe individual helpful group experiences, the group climate refers to the group environment as a whole - including the degree to which members are engaged with each other, avoidant, or in conflict.

The second category of measures are behavioural coding tools, which are used to describe and annotate discrete interactive transactions between group members (Bales, 1950; Cahill et al., 2008; Delucia-Waack, 1997). The aim of this approach, also referenced in the literature as in-session coding (Delucia-Waack, 1997) and process analysis of interaction (Beck \& Lewis, 2000), is to reliably measure classifications of behaviour occurring in a natural environment (Heath et al., 2010). Behavioural coding tools have the advantage of being exploratory and theory building (Fuhriman \& Burlingame, 1994a). However, they are often laborious and time-intensive for clinicians and/or researchers seeking to monitor group processes or link group processes with outcomes. New technologies have been used to automatically annotate interactions in a clinical population, for example 3D motion caption 
techniques (Lavelle et al., 2013). Whilst new technologies have much potential, they are currently limited to interaction laboratories. The present study therefore focused on questionnaire-based measures, which assess pre-defined group process phenomena. This includes questionnaires that can either be used by therapists, group members, or an independent observer.

Few attempts have been made to collate information on group process questionnaires for clinicians and/or researchers interested in selecting an appropriate measure. The American Group Psychotherapy Association compiled an evidence-based 'self-evaluation kit,' the CORE-R, aimed at aiding group therapists in their clinical practice (Strauss, Burlingame, \& Bormann, 2008). This included a list of questionnaires that focused on measuring group therapeutic relationships (Johnson, Burlingame, Olsen, Davies, \& Gleave, 2005). Measures included within the CORE-R assess both group members' relationship with the therapist and with the group (Jensen et al., 2012). More specifically, the measures in the CORE-R were chosen to represent one of three basic components of group phenomena outlined by Johnson and colleague's model of group therapeutic relationships (Johnson et al., 2005), including Positive Bond Relationship, Positive Working Relationship and Negative Working Relationship (Johnson et al., 2005). This model has been supported by six separate studies, including over 3000 participants from over 500 groups, across four countries (Burlingame, 2010).

More recently, Sodano and colleagues conducted a comprehensive review of group process, dynamics, and climate measures (Sodano et al., 2014). In their book chapter, they highlight a range of methodological approaches and tools available for measuring group processes. They also described the levels of reliability and validity for each approach. However, there are at least two important limitations within this literature. First, to the authors' knowledge, there has been no attempt to review the literature on group process 
measures using systematic methods to search and collect data. Hence, existing nonsystematic reviews are potentially subject to bias and errors in the study selection process (Egger, Davey-Smith, \& Altman, 2008). Second, no attempt has been made to assess the psychometric properties of studies describing the scale development of group process measures using standardised criterion. For example, Sodano and colleagues (2014) stated that measures included in their study must have at least a moderate level of reliability and construct validity. However, without explicit criterion definitions, what constitutes a moderate level of psychometric quality is not clear.

This study therefore sought to address these limitations by systematically reviewing and comprehensively appraising existing group process measures. In doing so, only articles that reported and/or evaluated the psychometric development of measures were included. Overall, the specific aims of the present study were to: develop an up-to-date summary of questionnaire-based group process measures used in a therapeutic group setting, and assess the psychometric properties of the identified questionnaire-based group process measures using an established set of quality criteria. This study sought to develop a list of measures that can be used by clinicians and researchers seeking to assess mechanisms of group process occurring in in group therapies.

\section{Methods}

\section{Literature Search Strategy}

The search process is summarised in Figure 1. A study protocol was developed using the Preferred Reporting Items for Systematic Reviews and Meta-Analyses Statement guidance (Moher et al. 2009). A systematic search of published questionnaires, which sought to measure group processes used within a group therapy setting, was conducted. Systematic principles were followed for searching and screening. Three search term categories were used, including 'measure' AND 'group process' AND 'group therapy.' The search terms 
included in the literature are outlined in the online supplementary Table 1. Search terms related to definitions of 'group process' sought to be as broad as possible. Whilst the group process search terms used included specific constructs related to the quality of therapeutic relationships — including cohesion alliance, climate and empathy_-broader terms such as nonverbal behaviour, group experience, therapeutic relationship, and social interaction were also used. Four electronic databases were searched, including PsycINFO (1806 to December 2018), Medline (1946 to December 2018), EMBASE (1974 to December 2018), and AMED (1806 to December 2018). As part of the literature search a number of related journal articles were hand searched, including the International Journal of Group Psychotherapy and Group Therapy.

Studies were included if: (a) group process was measured in the context of a therapeutic intervention or treatment involving more than two people other than the group leader/co-facilitator; (b) reference was made to scale development or the evaluation of psychometric properties, including reliability and /or validity, in the title or abstract; (c) they were published in English; and (d) they were published in a peer-reviewed journal. Studies were excluded if: (a) they were a review article (Potentially relevant studies within identified reviews were included in the grey literature hand search.); (b) group process was measured in a specific context of family or couples therapy; (c) personal attributes of an individual in a group were measured (e.g., group expectations or group leadership); (d) moment-to-moment interactions from segments of group sessions were measured using behavioural coding tools (This included any studies that involved the use of digital technologies, including video recordings equipment and/or other annotation software.); (e) there was a sample size of less than 50 participants, in accordance to Terwee and colleagues' (2007) established criteria on the psychometric properties of health outcome measures; and (f) they were only abstract publications or study protocols. 


\section{[INSERT FIGURE 1]}

\section{Data Extraction Procedure}

Titles and abstracts of studies were retrieved using the stated search strategy and inclusion/exclusion criteria. The lead researcher (the first author) first screened the titles and abstracts. Following this, a research assistant (the second author) independently re-screened $50 \%$ of all the identified studies. Any ambiguity was resolved with the lead researcher's primary supervisor (the fourth author). The first and second authors then both independently reviewed all studies included in the full paper review stage using a structured format developed by the first author to extract relevant information. Again, any ambiguity was resolved with the fourth author. Extracted information included details on the group process measure, including type of measure, number of items, construct being measured, how to use measure, and details on the development of the measure. Any missing data were requested from study authors.

\section{Appraisal of psychometric properties}

The quality assessment was undertaken using established criteria which assessed the development of questionnaire-based measures used in health (Terwee et al., 2007). In particular, these criteria assess the procedures used to develop questionnaires. Eight criteria outlined by Terwee and colleagues (2007) were used to determine the methodological quality of studies aimed at developing and evaluating group process measures. This included: (a) content validity (i.e., the extent to which concepts of interest are comprehensively represented by items in the questionnaire); (b) internal consistency (i.e., the assessment of whether items in scale of questionnaire are inter-correlated); (c) construct validity (i.e., the extent to which scores on a particular questionnaire relate to other measures in a manner that is consistent with theoretically derived hypotheses); (d) reproducibility-agreement (i.e., the extent to which the scores on repeated measures are close to each other); (e) reproducibility- 
reliability (i.e., the extent to which patients can be distinguished from each other, despite relative measurement error); (f) responsiveness (i.e., the ability of a questionnaire to detect clinically important changes over time); (g) floor and ceiling effects (i.e., number of respondents who achieved the lowest or highest possible score); (h) interpretability (i.e., degree to which one can assign qualitative meaning to quantitative scores). Terwee and colleagues' (2007) criteria guidance on assessing development procedures are outlined in the online supplementary Table 2.

Each item within the criterion was scored depending on whether there was an adequate design and appropriate reporting of statistics. If criteria for a given psychometric property were met, a "positive rating" of 2 was given. If criteria were doubtful in design, where a clear description of the outlined aspects was lacking, or only partial criteria were met for a given psychometric property, an "intermediate rating" of 1 was given. If there was no information provided on a given criteria, or criteria were explicitly not met, a "no rating" of 0 was given. Total scores for each measure and each quality criteria category across all measures are given.

Two raters (the first and second authors) rated the quality based on the operationalized definitions outlined in the online supplementary Table 2. Each rater independently conducted a quality appraisal of all studies which met the relevant inclusion/exclusion criteria in the following four steps: first, both raters independently conducted a quality appraisal from three randomly selected studies; second, the two raters reviewed and discussed their ratings together to ensure $100 \%$ rater agreement; third, the two raters both independently reviewed all the remaining papers using Terwee and colleague's (2007) quality criteria; finally the two raters a compared their ratings to ensure $100 \%$ agreement. Any ambiguity was resolved with the fourth author.

\section{Results}


A total of seventeen studies, which outlined twelve group process measures, met the inclusion criteria. An additional study/measure was identified during the hand searching stage. Therefore, a total of thirteen group process measures were reviewed and included in the psychometric assessment.

Six questionnaires focused on measuring helpful group processes associated with clinical outcomes and were categorised Therapeutic Group process measures. These measures included the Group Cohesiveness Scale (Wongpakaran et al., 2013), Therapeutic Factor Inventory (Joyce et al., 2011; Lese \& MacNair-Semands, 2000; MacNair-Semands et al., 2010), Group Cohesion Scale (Treadwell et al., 2001), Group Attitude Scale (Evans \& Jarvis, 1986), Curative Climate Instrument (Fuhriman et al., 1986) and the Scale for Evaluation of Group Counselling (Murillo et al., 1981). The characteristics of the six Therapeutic Group Process questionnaires are summarised in Table 1. Three versions of the Therapeutic Factor Inventory were identified and were, therefore, separately described in Table 1.

\section{[INSERT TABLE 1]}

The remaining seven questionnaires measured group processes more broadly, including both positive and negative group experiences, as well as individual and group level mechanisms. Hence these questionnaires were categorised as Overall Group Process measures. This included the Group Observational Measurement of Engagement (CohenMansfield et al., 2017), Factors Aspecific and Specific in Group Therapy (Marogna \& Caccamo, 2014), Social Exchange Scale (Brown et al., 2014), Ferrara Group Experiences Scale (Caruso et al., 2013), Group Questionnaire (Krogel et al., 2013), Group Sessions Rating Scale (Quirk et al., 2013) and Group Climate Questionnaire (MacKenzie, 1981; MacKenzie, 1983). The characteristics of the seven Overall Group Process questionnaires are summarised 
in Table 2. Two versions of the Group Climate Questionnaire were identified and were therefore separately described in Table 2 .

[INSERT TABLE 2]

Sixty-nine percent of studies described self-report questionnaires. The majority of questionnaires $(61 \%)$ were rated on either a five-point or seven-point Likert-type scale. The identified questionnaires were developed across a diverse range of therapeutic orientations and clinical and non-clinical populations. The number of items ranged from four items (Group Cohesiveness Scale) to 79 items (Scale of the Evaluation of Group Counselling).

The assessment of the psychometric properties of the thirteen included measures are summarised in Table 3. Scores for each of the eight categories outlined by Terwee and colleagues (2007) are given, in addition to total 'measure' and total 'category' scores. Based on the total measure scores, the Group Cohesiveness Scale (Wongpakaran et al., 2013), Therapeutic Factor Inventory-Short (MacNair-Semands et al., 2010), Therapeutic Factor Inventory-19 (Joyce et al., 2011), Group Questionnaire (Krogel et al., 2013) and Group Sessions Rating Scale scored highest in terms of their scale development quality. All measures except for the Social Exchange Scale (Brown et al., 2014) demonstrated good internal consistency.

[INSERT TABLE 3]

\section{Discussion}

To the authors' knowledge, the present study was the first to systematically review the literature on group process measures. Furthermore, this study was the first to use a clearly defined set of quality criteria to assess the psychometric properties of questionnaire-based group process measures. A list of measures that can be used by clinicians and/or researchers seeking to assess mechanisms of group process in group psychological therapies are presented. A total of thirteen questionnaire-based tools were organised into two categories. 
The first category outlined measures which assessed beneficial mechanisms of change relevant to clinical outcomes. This category included six measures and was titled Therapeutic Group Process measures. The second category of measures assessed overall group processes beyond helpful mechanisms, including positive and negative group experiences. This category included seven measures and was titled Overall Group Process measures.

The analysis of the psychometric properties highlighted several categories of quality criteria that were not reported. Only one measure, the Social Exchange Scale (Brown et al., 2014), was given a positive rating for content validity, regarded by Terwee and colleagues (2007) as the most important psychometric property. Twelve measures were given a 'no rating' for the reproducibility agreement criterion, where no information was given, or criteria were explicitly not met. Therefore the ability for the identified measures to assess change over time and longitudinal validity is limited or unclear. This is important when considering the applicability of these measures when assessing therapeutic change.

Furthermore, all measures scored a 'no rating' for the 'floor and ceiling effects' criterion, making interpretation of the content validity further difficult.

\section{Measuring Therapeutic Group Processes}

The findings from this study give insight into six measures that assess mechanisms of change inherent to beneficial, or helpful, group interactions. Three out of six measures within this category measured aspects of Yalom's proposed curative factors (Yalom \& Leszcz, 2005; Yalom, 1985). Therapeutic Factor Inventory-Short (TFI-S) (MacNair-Semands et al., 2010) and Therapeutic Factor Inventory-19 (Joyce et al., 2011) appear to be suitable instruments available for evaluating what group members find helpful about their group experience. Compared to the Group Cohesiveness Scale and the Curative Climate Instrument, the TFI-S and TFI-19 measure Yalom's curative factors more comprehensively-i.e., they seek to measure a broader range of curative factors. In terms of the reported psychometric 
properties, the TFI-S and TFI-19-item scored on par with the other measures identified. The

TFI-S demonstrated good internal consistency, construct validity, responsiveness and interpretability and the TFI-19 demonstrated some evidence of reproducibility and responsiveness.

Within the group therapy literature, the TFI-S is valued as a reliable and simple tool (Strauss et al., 2008) and features in the AGPA's CORE-R battery (Burlingame et al., 2006; Strauss et al., 2008). However, the TFI-S has more items than several other questionnaires in this category. The shorter TFI-19 is, therefore, arguably a more accessible choice of measure. Furthermore, the TFI-19 (Joyce et al., 2011) has been validated cross-culturally in a Japanese population (Kageyama et al., 2016).

The Group Cohesiveness Scale (Wongpakaran et al., 2013) also appears to be a suitable measure of helpful group processes. It had the highest total psychometric quality score and was the only measure which had a positive criterion validity score. Furthermore, it consists of only seven items. However, this measure is specifically focused on measuring group engagement and is therefore possibly too limited to be used alone.

\section{Measuring Overall Group Process}

The findings from this study highlight seven questionnaires which measure Overall Group Process, including both supportive and challenging group experiences. The Group Questionnaire (GQ) (Krogel et al., 2013) is arguably the most suitable questionnaire available for researchers seeking to measure group processes beyond those experienced as curative. An important strength of this measure is that it was developed to measure Johnson and colleagues' empirically robust theoretical model of group relationships (Johnson et al., 2005). The GQ was designed to combine concepts of "interpersonal structure of relationships," including member-leader, member-member, and member-group; and the "quality of the therapeutic relationship" in groups, including group cohesion, alliance, group climate, and 
empathy. Findings from the present study suggest that the GQ has good internal consistency and construct validity. These findings are also consistent with analyses from Thayer and Burlingame (2014), who also replicated the GQ's factor structure and correlated the GQ with measures from which it was originally developed.

The GQ is referenced in a previous review of measures related to group process, dynamics and interventions (Sodano et al., 2014). In this review, it is noted that populationspecific norms from Krogel and colleagues' sample (Krogel et al., 2013)—including inpatient, non-clinical and counselling centre groups - allow for the comparison of GQ scores with relevant normative group scores. A more recent study further supported the GQ factor structure (Janis et al., 2018). Janis and colleagues (2018) used results from six GQ studies conducted across a diverse clinical and nonclinical sample of 2479 participants further supporting the implementation of unique GQ norms.

Findings from this current study highlight that popular measures are not necessarily psychometrically robust. The Group Climate Questionnaire-Short (GCQ-S) (MacKenzie, 1983) has been cited as the most commonly used and extensively validated group process measure in the group psychotherapy literature (Burlingame et al., 2004; Johnson et al., 2006; Strauss et al., 2008). Furthermore, like the TFI, it is also recommended in the AGPA's CORE-R battery of group process measures (Burlingame et al., 2006; Strauss et al., 2008). However findings from the present study highlight that the Group Climate Questionnaire (MacKenzie, 1981) and the Group Climate Questionnaire-Short (MacKenzie, 1983) have relatively low scale development quality scores compared to other available tools. The discrepancy between the GCQ-S' low psychometric properties and high popularity might be because the GCQ-S is an extremely user-friendly tool, consisting of only 12 items and can be flexibly used by either a group member, group leader, or observer (DeChavez et al., 2000). 


\section{Limitations}

This present study is limited to questionnaire-based measures of group process phenomena and does not include moment-to-moment behavioural coding tools (Davis et al., 2000) or open-ended qualitative measures of group process (Strauss et al., 2008).

Questionnaires are likely to be the most appropriate approach for clinicians who have busy practices, or researchers seeking to incorporate feedback on group processes during ongoing groups (Burlingame et al., 2015; Slone et al., 2015). However, behavioural coding tools (Bales, 1950; Cahill et al., 2008; Delucia-waack, 1997) have the advantage of reliably measuring fine-grain interactive behaviours often too subtle to the human eye. Furthermore, they can be measured and analysed using automated digital technologies (Heath et al., 2007). Compared to questionnaires, behavioural coding tools are a more bottom-up exploratory approach, where simple behavioural categories and/or statements can be combined or aggregated to form multiple variations of interactive behaviours (Davis et al., 2000). Hence this approach might be more suitable for researchers and/or clinicians seeking to identify less understood group processes (Fuhriman \& Burlingame, 1994a).

A second limitation of the present study is that the appraisal of psychometric properties was limited to studies that reported scale development. To address this limitation, quality appraisal scores were given for newer revisions of scales, where reference was made to scale development or the evaluation of psychometric properties. This included separate psychometric quality scores for the GCQ and GCQ-Short, and the TFI, TFI-S, and TFI-19. In addition to this, the present study reported detailed separate quality assessment ratings for each of the eight quality criteria for all included measures, as recommended by Terwee and colleagues (2007).

A third methodological limitation to be considered is that a high number of studies did not meet inclusion criteria and were excluded during the screening stages. Whilst 
systematic principles were followed for searching and screening potentially relevant studies, the search term strategy may have been too comprehensive. Identifying measures that met inclusion criteria was therefore a challenging task. To address this limitation, stringent interrater procedures were followed. A second rater re-extracted $50 \%$ of the studies initially identified and independently reviewed all studies included in the full-paper review stage. Furthermore, both the lead researcher and an independent researcher completed all quality ratings. Future researchers may benefit from refining the search strategy to reduce the number of irrelevant studies and minimise risks of error at the screening stages.

\section{Implications}

As noted by Lo Coco and colleagues (2015) there is a need to "bridge the gap between science and practice in group psychotherapy" (p.288). The results from the current study help address this need, by providing researchers and clinical practitioners with a systematic evaluative collation of group process measures for research and clinical use. To aid researchers and clinicians in their decision making process, the identified questionnaires are organised into Therapeutic Group Process measures and Overall Group Process categories. The Therapeutic Factor Inventory-Short (MacNair-Semands et al., 2010) and the Group Questionnaire (Krogel et al., 2013) are recommended questionnaires from these respective categories.

The results from this study demonstrate the importance of testing the psychometric properties of existing group process measures. To date, none of the identified studies referenced absolute measurement error-i.e., the degree to which repeated scores across similar measures are in line with each other. Furthermore, all included studies failed to define a minimal important change. Therefore evaluating the interpretability of the identified measures was a challenge - in particular, their applicability to assessing therapeutic change. 
If these psychometric properties were evaluated, it is recommended that researchers report these important criteria.

It is also recommended that when selecting a group process measure, clinicians and researchers consider issues related to content validity — described as the degree to which group process concepts of interest are adequately represented in the chosen questionnaire (Terwee et al., 2007). For a positive rating of this criterion, Terwee and colleagues (2007) state that authors should highlight the involvement of the target population during item selection, in addition to providing a clear description of the measurement aim, target population and concepts. Whilst most authors gave a clear description of the measurement aim and concepts of the questionnaire, Brown and colleagues' (2014) were the only authors who explicitly reported that they involved the target population during the development of the Social Exchange Scale. Hence most studies scored zero for this quality criterion. It is not clear whether authors failed to involve the target population in the item selection/reduction phase of questionnaire development, or failed to report this. Nonetheless, future researchers seeking to use or adapt a given group process measure would benefit from ensuring that items are piloted with the clinical population of interest first.

Current guidance for measuring and monitoring group processes in group therapies recommend questionnaire-based instruments (Bernard et al., 2008). However, as noted, future researchers would benefit from reviewing relevant behavioural coding tools, which allow for a bottom-up exploration of less defined group processes. The present study gives insight into how behavioural coding tools can be systematically identified and evaluated in future studies_-including strategies for searching, screening, and appraising results from the group therapy literature. Whilst qualitative methods are less commonly reported within the literature, this approach also has the advantage of being theory-building and is also recommended within group therapy guidelines (Strauss et al., 2008). In the CORE-R it is 
argued that it is important to gain a "qualitative perspective on group experiences" (p. 1233) when measuring group processes (Strauss et al., 2008). In line with this guidance, a critical incidence approach, where group members are asked about what incidents in the group were critical to them using a series of open-ended questions may also be a helpful exploratory approach (Strauss et al., 2008). Depending on the resources available, we argue that future researchers seeking to identify and measure group process mechanisms would benefit from using a combination of questionnaire-based, behavioural coding and qualitative approaches.

\section{Conclusion}

A list of thirteen questionnaire-based group process measures were described and evaluated, providing a valuable source of reference for clinicians and researchers. The Therapeutic Factor Inventory-Short (MacNair-Semands et al., 2010) and the Therapeutic Factor Inventory-19 (Joyce et al., 2011) are recommended for those seeking to assess beneficial mechanisms of change relevant to clinical outcomes. However, if one is interested in measuring overall group processes, then Group Questionnaire (Krogel et al., 2013) is recommended as the most appropriate measure. This might be more relevant in an exploratory study seeking to identify both beneficial and challenging aspects of interactive group mechanisms relevant to clinical outcomes. Future studies should consider validating these measures further. In particular, studies should focus on developing the content validity of these scales. Furthermore, future research would benefit from considering behavioural coding tools, as well as qualitative methods when measuring the therapeutic group process.

Acknowledgements: This project was supported by University College London as part of a Doctorate in Clinical Psychology thesis project.

Declaration of interest statement: None to declare. 


\section{References}

Bakali, J., Wilberg, T., Klungsøyr, O., \& Lorentzen, S. (2013). Development of group climate in short-and long-term psychodynamic group psychotherapy. International Journal of Group Psychotherapy, 63(3), 366-393. https://doi.org/10.1007/s10464-013-9621-3

Bales, R. F. (1950). Interaction process analysis; a method for the study of small groups. Addison-Wesley.

Bernard, H., Burlingame, G., Flores, P., Greene, L., Joyce, A., Kobos, J.C., Leszcz, M., MacNair-Semands, Piper, W.E., McEneaney, A.M., \& Feirman D. (2008). Clinical Practice Guidelines for Group Psychotherapy. International Journal of Group Psychotherapy, 58(4), 445542.

Brown, L.D., Tang, X., \& Hollman, R.L. (2014). The structure of social exchange in self-help support groups: Development of a measure. American journal of community psychology, 53(2), 83-95. https://doi.org/10.1007/s10464-013-9621-3

Burlingame, G. M., MacKenzie, K. R., \& Strauss, B. (2004). Small group treatment: Evidence for effectiveness and mechanisms of change. In M. J. Lambert (Ed.), Handbook of Psychotherapy and Behavior Change (5th ed., pp. 647-696). Wileys \& Sons.

Burlingame, G., Strauss, B., Joyce, A., MacKenzie, K., Ogrodniczuk, J., \& Taylor, S. (2006). CORE battery: A revision and update. American Group Psychotherapy Association.

Burlingame, G., Gleave, R., Erekson, D., Nelson, P., Olsen, J., Thayer, S., \& Beecher, M. (2015). Differential effectiveness of group, individual, and conjoint treatments: An archival analysis of OQ-45 change trajectories. Psychotherapy Research, 26(5), 556-572.

https://doi.org/10.1080/10503307.2015.1044583 
Burlingame, G. M., Strauss, B., \& Joyce, A. S. (2013). Change mechanisms and effectiveness of small group treatments. In M. J. Lambert (Ed.), Handbook of Psychotherapy and Behavior Change (6th ed., pp. 640-689). Wileys \& Sons.

Burlingame, G. M. (2010). Small group treatments: Introduction to special section. Psychotherapy Research, $20(1), 1-7$. https://doi.org/10.1080/10503301003596551

Burlingame, G. M. (2014). Some Observations on How the Practice of Small Group Treatments Can Be Built Upon the Foundation of Research: A 30+ Year Perspective. International Journal of Group Psychotherapy, 64(4), 567-583. https://doi.org/10.1521/ijgp.2014.64.4.567

Cahill, J., Barkham, M., Hardy, G., Gilbody, S., \& Richards, D. (2008). A review and critical appraisal of measures of therapist-patient interactions in mental health settings. Health Technology Assessment, 12(24), 68. https://doi.org/10.1108/cgij.2009.24814aaf.003

Campbell, N.C., Murray, E., Darbyshire, J., Emery, J., Farmer, A., G., Frances, . . Kinmonth, Louise, A. (2007). Designing and evaluating complex interventions to improve health care. British Medical Journal, 334(7591), 455.https://doi.org/10.1136/bmj.39108.379965.be

Caruso, R., Grassi, L., Biancosino, B., Marmai, L., Bonatti, L., Moscara, M., . . Priebe, S. (2013). Exploration of experiences in therapeutic groups for patients with severe mental illness: development of the Ferrara group experiences scale (FE-GES). BMC Psychiatry, 13(242). https://doi.org/10.1186/1471-244x-13-242

Chapman, L., Burlingame, G., Gleave, R., Rees, F., Beecher, M., \& Porter, G. (2012). Clinical prediction in group psychotherapy. Psychotherapy Research, 22(6), 673-681.https://doi.org/10.1080/10503307.2012.702512 
Cohen-Mansfield, J., Hai, T., \& Comishen, M. (2017). Group engagement in persons with dementia: the concept and its measurement. Psychiatry Research, 251, 237-243.https://doi.org/10.1016/j.psychres.2017.02.013

Davis, M., Budman, S.H., \& Soldz, S. (2000). The individual group member interpersonal process scale. In A. P. Beck \& C. M. Lewis (Eds.), The process (pp. 283-308). American Psychological Association.

DeChavez, M. G., Gutierrez, M., Ducaju, M., \& Fraile, J. C. (2000). Comparative Study of the Therapeutic Factors of Group Therapy in Schizophrenic Inpatients and Outpatients. Group Analysis, 33(2), 251-264. https://doi.org/10.1177/0533316400332006

Delucia-waack, J. L. (1997). Measuring the effectiveness of group work: A review and analysis of process and outcome measures. The Journal for Specialists in Group Work, 22(4), 277-293. https://doi.org/10.1080/01933929708415531

Egger, M., Davey-Smith, G., \& Altman, D. (2008). Systematic reviews in health care: meta-analysis in context (2 ${ }^{\text {nd }}$ ed.). John Wiley \& Sons.

Evans, N. J, \& Jarvis, P. A. (1986). The group attitude scale: A measure of attraction to group. Small group behavior, 17(2), $203-216$. https://doi.org/10.1177/104649648601700205

Fuhriman, A., Drescher, S., Hanson, E., Henrie, R., \& Rybicki, W. (1986). Refining the Measurement of Curativeness: An Empirical Approach. Small Group Research, 17(2), 186-201. https://doi.org/10.1177/104649648601700204

Fuhriman, A., \& Burlingame, G. M. (1994a). Handbook of group psychotherapy: An empirical and clinical synthesis. Wiley.

Fuhriman, A., \& Burlingame, G. M. (1994b). Measuring small group process a methodological application of chaos theory. Small Group Research, 25(4), 502-519. https://doi.org/10.1177/1046496494254005 
Garcia-Cabeza, I., Ducaju, M., Chapela, E., \& Gonzalez de Chavez, M. (2011). Therapeutic Factors in Patient Groups with Psychosis. Group Analysis, 44(4), 421-438. https://doi.org/10.1177/0533316411413522

Heath, C, Hindmarsh, J, \& Luff, P. (2010). Video in qualitative research: analysing social interaction in everyday life. Introducing qualitative methods. California, USA: Sage.

Heath, C., Luff, P., \& Sanchez S. M. (2007). Video and qualitative research: analysing medical practice and interaction. Medical education, 4l(1), 109-116. https://doi.org/10.1111/j.1365-2929.2006.02641.x

Janis, R. A, Burlingame, G. M., \& Olsen, J. A. (2018). Developing a therapeutic relationship monitoring system for group treatment. Psychotherapy, 55(2), 105. https://doi.org/10.1037/pst0000139

Jensen, D. R., Abbott, M. K., Beecher, M. E., Griner, D., Golightly, T. R., \& Cannon, J. N. (2012). Taking the pulse of the group: The utilization of practice-based evidence in group psychotherapy. Professional Psychology: Research and Practice, 43(4), 388. https://doi.org/10.1037/a0029033

Johnson, J., Pulsipher, D., Ferrin, S., Burlingame, G. M., Davies, R., \& Gleave, R. (2006). Measuring group processes: A comparison of the GCQ and CCI. Group Dynamics: Theory, Research, and Practice, 10(2), 136-145. https://doi.org/10.1037/1089-2699.10.2.136

Johnson, J. E., Burlingame, G. M., Olsen, J. A., Davies, D. R., \& Gleave, R. L. (2005). Group Climate, Cohesion, Alliance, and Empathy in Group Psychotherapy: Multilevel Structural Equation Models. Journal of Counseling Psychology, 52(3), 310-321.

https://doi.org/10.1037/0022-0167.52.3.310 
Joyce, A. S., MacNair-Semands, R., Tasca, G. A., \& Ogrodniczuk, J. S. (2011). Factor structure and validity of the Therapeutic Factors Inventory-Short Form. Group Dynamics: Theory, Research, and Practice, 15(3), 201-219. https://doi.org/10.1037/a0024677

Kageyama, M., Nakamura, Y., Kobayashi, S., \& Yokoyama, K. (2016). Validity and reliability of the Japanese version of the Therapeutic Factors Inventory-19: A study of family peer education self-help groups. Japan Journal of Nursing Science, 13(1), 135-146. https://doi.org/10.1111/jjns.12098

Krogel, J., Burlingame, G. M., Chapman, C., Renshaw, T., Gleave, R., Beecher, M., \& MacNair-Semands, R. (2013). The Group Questionnaire: A clinical and empirically derived measure of group relationship. Psychotherapy Research, 23(3), 344-354. https://doi.org/10.1080/10503307.2012.729868

Lavelle, M., Healey, P. G., \& McCabe, R. (2013). Is nonverbal communication disrupted in interactions involving patients with schizophrenia? Schizophrenia Bulletin, 39(5), 1150-1158. https://doi.org/10.1093/schbul/sbs091

Lese, K., \& MacNair-Semands, R. R. (2000). The Therapeutic Factors Inventory: Development of a Scale. Group, 24(4), 303-317.

Lo Coco, G., Salvatore, G., Prestano, C., \& Burlingame, G.M. (2015). Current issues on group psychotherapy research: An overview. In: Psychotherapy Research (O.C.G Gelo et al., eds.), 279-292. Springer-Verlag. https://doi.org/10.1007/978-3-7091-1382-0_14

Lo Coco, G., Tasca, G. A., Hewitt, P. L., Mikail, S. F., \& Kivlighan Jr, D. M. (2019). Ruptures and repairs of group therapy alliance. An untold story in psychotherapy research. Research in Psychotherapy: Psychopathology, Process and Outcome, 22(1), 58-70.

https://doi.org/10.4081/ripppo.2019.352 
MacKenzie, R. (1981). Measurement of group climate. International Journal of Group Psychotherapy, 31(3), 287-295. https://doi.org/10.1080/00207284.1981.11491708

MacKenzie, K. R. (1983). The clinical application of a group measure. In R. R. Dies \& K. R. MacKenzie (Eds.), Advances in group psychotherapy: Integrating research and practice (pp. 159-170). International Universities Press.

MacNair-Semands, R.R., Ogrodniczuk, J., \& Joyce, A. (2010). Structure and Initial Validation of a Short Form of the Therapeutic Factors Inventory. International Joural of Group Psychotherapy, 60(2), 245-281. https://doi.org/10.1521/ijgp.2010.60.2.245

Marmarosh, C. L. (2018). Introduction to special issue: Feedback in group psychotherapy. Psychotherapy, 55(2), 101. https://doi.org/10.1037/pst0000178

Marogna, C., \& Caccamo, F. (2014). Analysis of the process in brief psychotherapy group: the role of therapeutic factors. Research in Psychotherapy: Psychopathology, Process and Outcome, 43-51. https://doi.org/10.4081/ripppo.2014.161

McCrone, P. (2008). Paying the price: the cost of mental health care in England to 2026. https://www.kingsfund.org.uk/sites/default/files/Paying-the-Price-the-cost-of-mental-health-care-England-2026-McCrone-DhanasiriPatel-Knapp-Lawton-Smith-Kings-Fund-May-2008_0.pdf

Moher, D., A. Liberati, J. Tetzlaff and D. G. Altman (2009). Preferred reporting items for systematic reviews and meta-analyses: The PRISMA statement. Annals of Internal Medicine, 151(4). https://doi.org/10.7326/0003-4819-151-4-200908180-00135 
Murillo, N., Shaffer, P., \& Michael, W. B. (1981). The development and validation of a preliminary measure for student evaluation of group counseling experiences. Educational and Psychological Measurement, 41(2), 463-472. https://doi.org/10.1177/001316448104100225

Priebe, S., Savill, M., Reininghaus, U., Wykes, T., Bentall, R., Lauber, C., . . Eldridge, S. (2013). Effectiveness and cost-effectiveness of body psychotherapy in the treatment of negative symptoms of schizophrenia - a multi-centre randomised controlled trial. BioMed Central, 13(26), 1-8. https://doi.org/10.1186/1471-244x-13-26

Quirk, K., Miller, S., Duncan, B., \& Owen, J.. (2013). Group Session Rating Scale: Preliminary psychometrics in substance abuse group interventions. Counselling and Psychotherapy Research, 13(3), 194-200. https://doi.org/10.1080/14733145.2012.744425

Slone, N., Reese, R., Mathews-Duvall, S., \& Kodet, J. (2015). Evaluating the efficacy of client feedback in group psychotherapy. Group Dynamics: Theory, Research, and Practice, 19(2), 122. https://doi.org/10.1037/e533762014-001

Sodano, S. M., Guyker, W. M., DeLucia-Waack, J. L., Cosgrove, H. D., Altabef, D. T., \& Amos, B. S. (2014). Measures of group process, dynamics, climate behaviour, and outcome: A review. In J. L. DeLucia-Waack, C. Kalodner, \& M. T. Riva (Eds.), The handbook of group counselling and psychotherapy (2nd ed., pp. 159-177). Sage.

Strauss, B., Burlingame, G. M., \& Bormann, B. (2008). Using the CORE-R battery in group psychotherapy. Journal of Clinical Psychology, 64(11), 1225-1237. https://doi.org/10.1002/jclp.20535 
Terwee, C. B., Bot, S., de Boer, M., van der W., Daniëlle A., Knol, D., Dekker, J., . . de Vet, H. (2007). Quality criteria were proposed for measurement properties of health status questionnaires. Journal of clinical epidemiology, 60(1), 34-42.

https://doi.org/10.1016/j.jclinepi.2006.03.012

Thayer, S. D., \& Burlingame, G. M. (2014). The validity of the Group Questionnaire: Construct clarity or construct drift? Group Dynamics: Theory, Research, and Practice, 18(4), 318. https://doi.org/10.1037/gdn0000015

Treadwell, T., Lavertue, N., Kumar, V. K, \& Veeraraghavan, V. (2001). The group cohesion scale-revised: reliability and validity. Journal of Group Psychotherapy, Psychodrama and Sociometry, 54(1), 3.

Wongpakaran, T., Wongpakaran, N., Intachote-Sakamoto, R., \& Boripuntakul, T. (2013). The group cohesiveness scale (GCS) for psychiatric inpatients. Perspectives in psychiatric care, 49(1), 58-64. https://doi.org/10.1111/j.1744-6163.2012.00342.x

Yalom, I., \& Leszcz, M. (2005). The Theory and Practice of Group Psychotherapy (5th edition ed.). Harper Collins.

Yalom, I. (1985). The theory and practice of group psychotherapy. Basic Books. 
Figure 1. Search process of literature

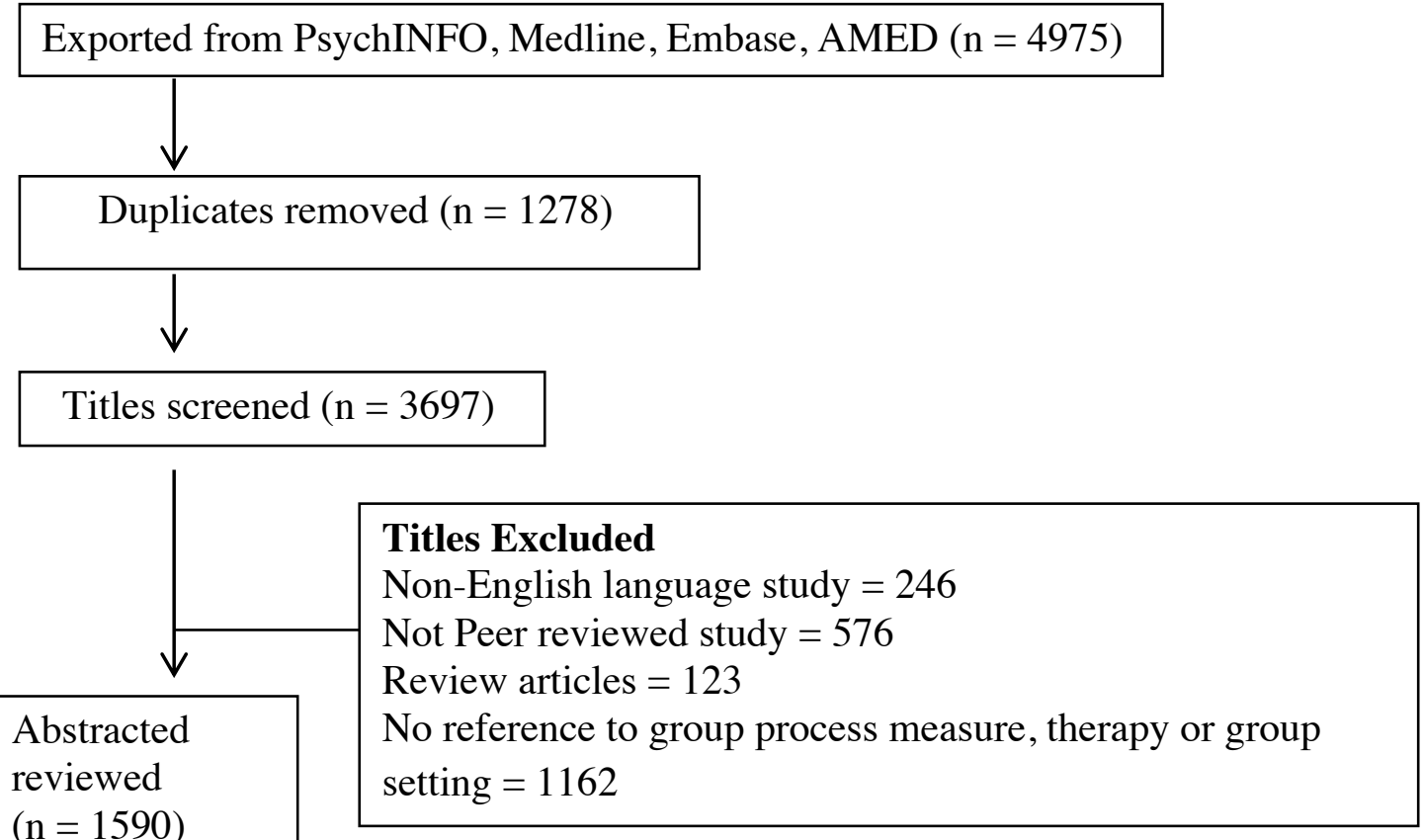

$(\mathrm{n}=1590)$

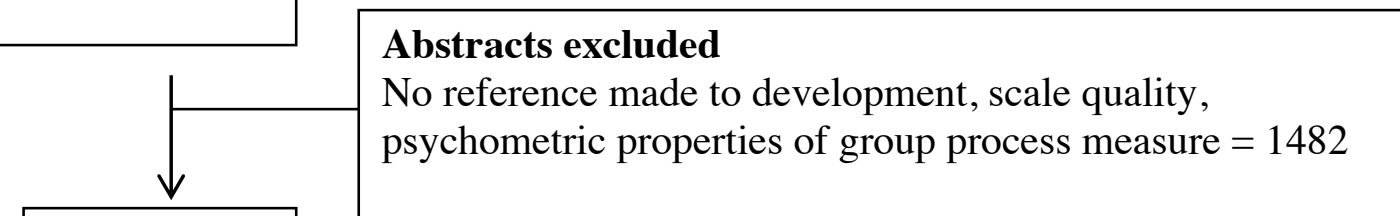

Full papers

reviewed

$(\mathrm{n}=108)$

\section{Papers Excluded}

Sample less than $50=11$

Not group therapy setting $=5$

Family measure only $=5$

Not English $=6$

No reference to psychometric development $=8$

Measured person attributes, not group process $=14$

Measured moment to moment interactions $=10$

Used technology $=26$

Qualitative paper $=4$ 
Studies included from literature search $=17$

Studies identified from hand search $=1$ 
Table 1. Characteristics of measures in the 'therapeutic group process' category

\begin{tabular}{|c|c|c|c|c|}
\hline Measure & Study & Measurement details & $\begin{array}{c}\text { Number of items / } \\
\text { delivery }\end{array}$ & $\begin{array}{l}\text { Group characteristics, } \\
\text { sample size, location }\end{array}$ \\
\hline \multirow[b]{2}{*}{$\begin{array}{l}\text { Therapeutic } \\
\text { Factor Inventory }\end{array}$} & $\begin{array}{c}\text { (Lese \& } \\
\text { MacNair- } \\
\text { Semands, 2000) }\end{array}$ & $\begin{array}{l}\text { Therapeutic Factor Inventory: Measures Yalom's } 11 \text { curative } \\
\text { group factors; including instillation of hope, universality, } \\
\text { imparting information, altruism, corrective recapitulation of the } \\
\text { primary family group, development of socialising techniques, } \\
\text { imitative behaviour, interpersonal learning, group cohesiveness, } \\
\text { catharsis, existential learning. }\end{array}$ & $\begin{array}{l}\text { 99-items / self-report, } \\
\text { seven-point Likert } \\
\text { scale }\end{array}$ & $\begin{array}{l}\text { Counselling and support } \\
\text { groups for } \\
\text { undergraduate/graduate } \\
\text { college students, USA } \\
(\mathrm{N}=77,76 \% \text { female })\end{array}$ \\
\hline & $\begin{array}{l}\text { (MacNair- } \\
\text { Semands et al., } \\
\text { 2010) }\end{array}$ & $\begin{array}{l}\text { Therapeutic Factor Inventory-Short: Measures four broad } \\
\text { therapeutic factors more globally; including instillation of hope, } \\
\text { secure emotional expression, awareness of relational impact and } \\
\text { social learning. }\end{array}$ & $\begin{array}{l}\text { 44-item / self-report, } \\
\text { seven-point Likert } \\
\text { scale. }\end{array}$ & $\begin{array}{l}\text { Self-awareness groups } \\
(\mathrm{N}=174,65 \% \text { female }) \text { at } \\
\text { a day treatment } \\
\text { program, Canada. }\end{array}$ \\
\hline
\end{tabular}


Table 1 continued.

\section{Measure}

The Group

Cohesion scale-

Revised

Study Measurement details

(Treadwell et

al., 2001)

Measures cohesion among group members in terms of interaction

and communication. Items include whether group members felt

free to share information, feelings of unity and togetherness and receptiveness to feedback.
Number of items /

delivery

25-items / self-report,

four-point scale
Group characteristics, sample size, location

Eight experiential

training courses

$(\mathrm{N}=110)$ cognitive and

psychodramatic

techniques, USA.

\begin{tabular}{ccl}
\hline $\begin{array}{c}\text { Group attitude } \\
\text { scale* }\end{array}$ & $\begin{array}{c}\text { Evans \& Jarvis, } \\
\text { 1986) }\end{array}$ & $\begin{array}{l}\text { Measures attraction to group, defined as an individual's desire to } \\
\text { identify with and be an accepted member of the group. Focuses on } \\
\text { evaluating group member feelings about the group rather than } \\
\text { behaviour in the group. }\end{array}$
\end{tabular}
behaviour in the group.

\begin{tabular}{cl} 
Curative & (Fuhriman et al. \\
Climate & 1986) \\
Instrument & \\
& \\
& \\
\hline Scale for the & (Murillo et al., \\
Evaluation of & 1981) \\
Group & \\
Counselling & \\
\end{tabular}

Measures four of Yalom's curative group factors. Subscales

include: 1) cohesion (forces within a group that draw it together);

2) catharsis (emotional expression of self); 3 ) interpersonal

learning (receiving information about behaviour from other group

members) and 4) insight (seeing and experiencing self in a new

way).

Measures group counselling experiences. Based on Yalom's

curative group factors, including 1) satisfying experience

(catharsis, cohesiveness, group satisfaction, counsellor

effectiveness, openness); 2) interpersonal learning (altruism,

interpersonal learning, cohesiveness); 3) increasing self-

confidence (instillation of hope, universality)
0 items / self-report,

nine-point Likert Scale

26 groups $(\mathrm{N}=178)$;

unstructured/ semistructured growth, assertion-training, Gestalt, community health groups, USA. 20 items / self-report, five-point Likert scale Outpatient therapy or personal growth groups $(\mathrm{N}=161)$; veteran, community mental, counselling, centres, USA

79 items / self-report,
five-point Likert scale 18 counselling groups for personal growth, weight reduction, assertion training and stress management, USA ( $\mathrm{N}=99$ )

\footnotetext{
* Reference made to three earlier scale development studies although these were not published as peer-reviewed articles, hence not included.
} 
Table 2. Characteristics of measure in the 'overall group process' category

\begin{tabular}{|c|c|c|c|c|}
\hline Measure & Study & Measurement details & $\begin{array}{l}\text { Number of items / } \\
\text { delivery }\end{array}$ & $\begin{array}{l}\text { Group characteristics, sample } \\
\text { size, location }\end{array}$ \\
\hline $\begin{array}{l}\text { Factors } \\
\text { Aspecific and } \\
\text { Specific in } \\
\text { Group Therapy }\end{array}$ & $\begin{array}{l}\text { (Marogna \& } \\
\text { Caccamo, 2014) }\end{array}$ & $\begin{array}{l}\text { Measures therapeutic group factors that are specific (related to } \\
\text { a theoretical model used by therapist) and non-specific (not } \\
\text { related to a theoretical model/specific technique used by } \\
\text { therapy). }\end{array}$ & $\begin{array}{l}\text { 41-items / self- } \\
\text { report, five-point } \\
\text { Likert scale }\end{array}$ & $\begin{array}{l}52 \text { group therapies }(\mathrm{N}=167,39 \% \\
\text { female); range of mental health } \\
\text { diagnoses from mental health } \\
\text { centres, family clinics } \\
\text { psychiatric hospitals, Italy }\end{array}$ \\
\hline $\begin{array}{l}\text { Social exchange } \\
\text { scale* }\end{array}$ & $\begin{array}{l}\text { (Brown et al., } \\
2014 \text { ) }\end{array}$ & $\begin{array}{l}\text { Measures social exchange during self-help support group } \\
\text { meetings. Seven subscales assess: 1) emotional support } \\
\text { provided; 2) experiential information provided; 3) emotional } \\
\text { support received; 4) experiential information received; 5) } \\
\text { unwanted behaviours received; 6) humour exchanged; and 7) } \\
\text { exchanges outside meetings. }\end{array}$ & $\begin{array}{l}29 \text { items / self- } \\
\text { report }\end{array}$ & $\begin{array}{l}18 \text { parenting self-help groups } \\
(\mathrm{N}=194,99 \% \text { female); all } \\
\text { parent-led, USA. }\end{array}$ \\
\hline
\end{tabular}


Table 2 continued.

\begin{tabular}{|c|c|c|c|c|}
\hline Measure & Study & Measurement details & $\begin{array}{l}\text { Number of items / } \\
\text { delivery }\end{array}$ & $\begin{array}{l}\text { Group characteristics, sample } \\
\text { size, location }\end{array}$ \\
\hline
\end{tabular}

(agreement on therapeutic tasks/goals), and negative

relationship (conflict and empathic failure).

\begin{tabular}{|c|c|c|c|c|}
\hline $\begin{array}{l}\text { Group Sessions } \\
\text { Rating Scale }\end{array}$ & $\begin{array}{l}\text { (Quirk et al., } \\
\text { 2013) }\end{array}$ & $\begin{array}{l}\text { Measures group alliance in terms of: 1) relationships (feeling } \\
\text { respected and understood or not); 2) goals (working topics of } \\
\text { interest or not); 3) acceptability of approach (whether group } \\
\text { approach/leadership was adequate enough or not); 4) overall fit } \\
\text { (whether group was suitable or not) }\end{array}$ & $\begin{array}{l}\text { Four item visual } \\
\text { analogue scale. }\end{array}$ & $\begin{array}{l}\text { Five open therapy groups for } \\
\text { issues related to substance abuse } \\
(\mathrm{N}=105,58 \% \text { female })\end{array}$ \\
\hline $\begin{array}{l}\text { Group Climate } \\
\text { Questionnaire }\end{array}$ & $\begin{array}{l}\text { (MacKenzie, } \\
1981 \text { ) }\end{array}$ & $\begin{array}{l}\text { Group Climate Questionnaire: Measures group environment. } \\
\text { Eight subscales assess; 1) engagement, 2) disclosure, 3) } \\
\text { support, 4) conflict, 5) challenge, 6) practicality, 7) cognition, } \\
\text { and 8) control. }\end{array}$ & $\begin{array}{l}32 \text { items / self- } \\
\text { report, observer- } \\
\text { rated, seven-point } \\
\text { Likert scale }\end{array}$ & $\begin{array}{l}\text { Psychiatric outpatient } \\
\text { psychotherapy, supportive, } \\
\text { activity and social groups, } \\
(\mathrm{N}=119,56 \% \text { female })\end{array}$ \\
\hline
\end{tabular}

*Consisted of two studies, part two are reported in this review. 
Table 3. Psychometric quality scores for the 13 included measures

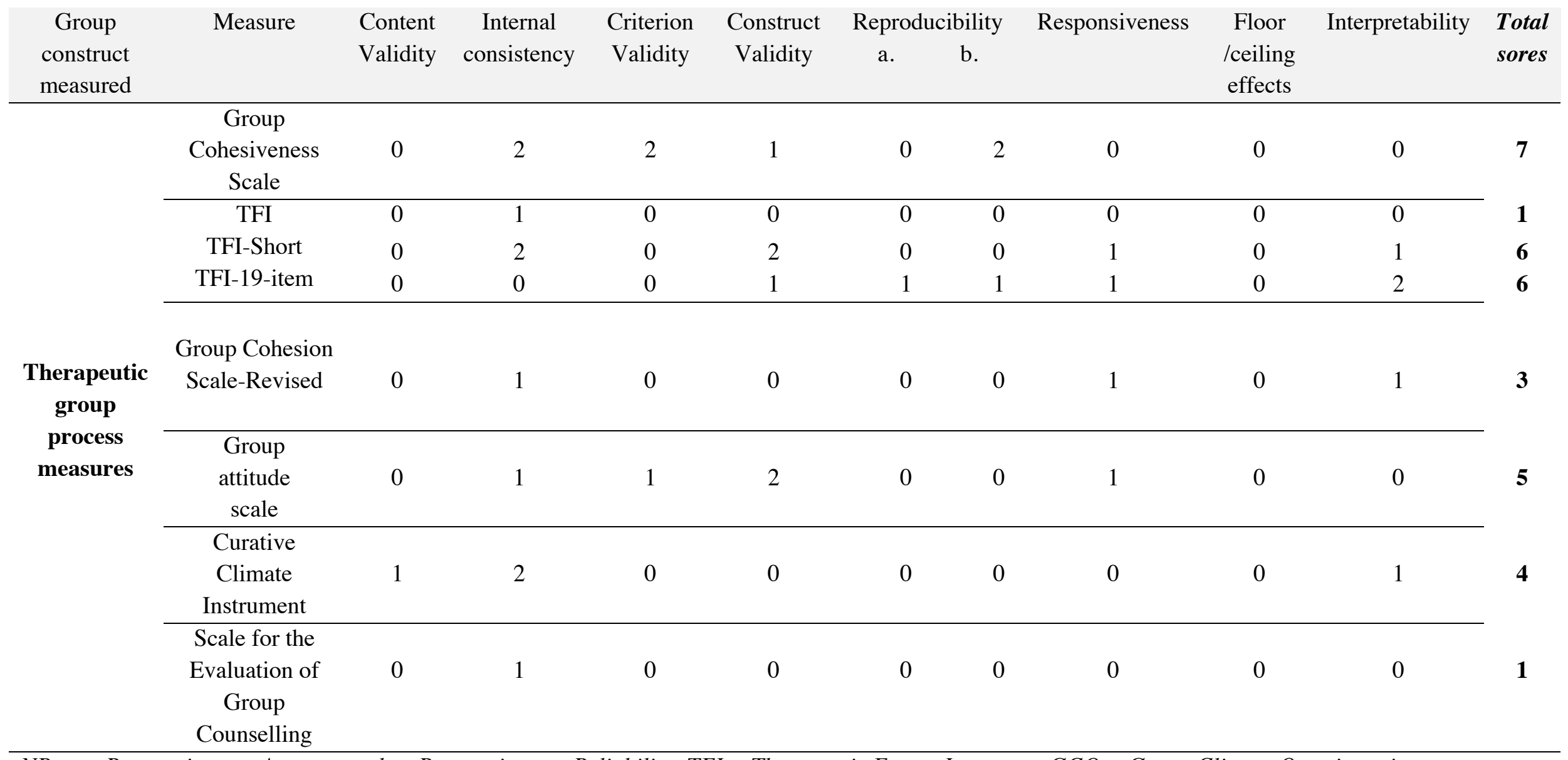


Table 3 continued.

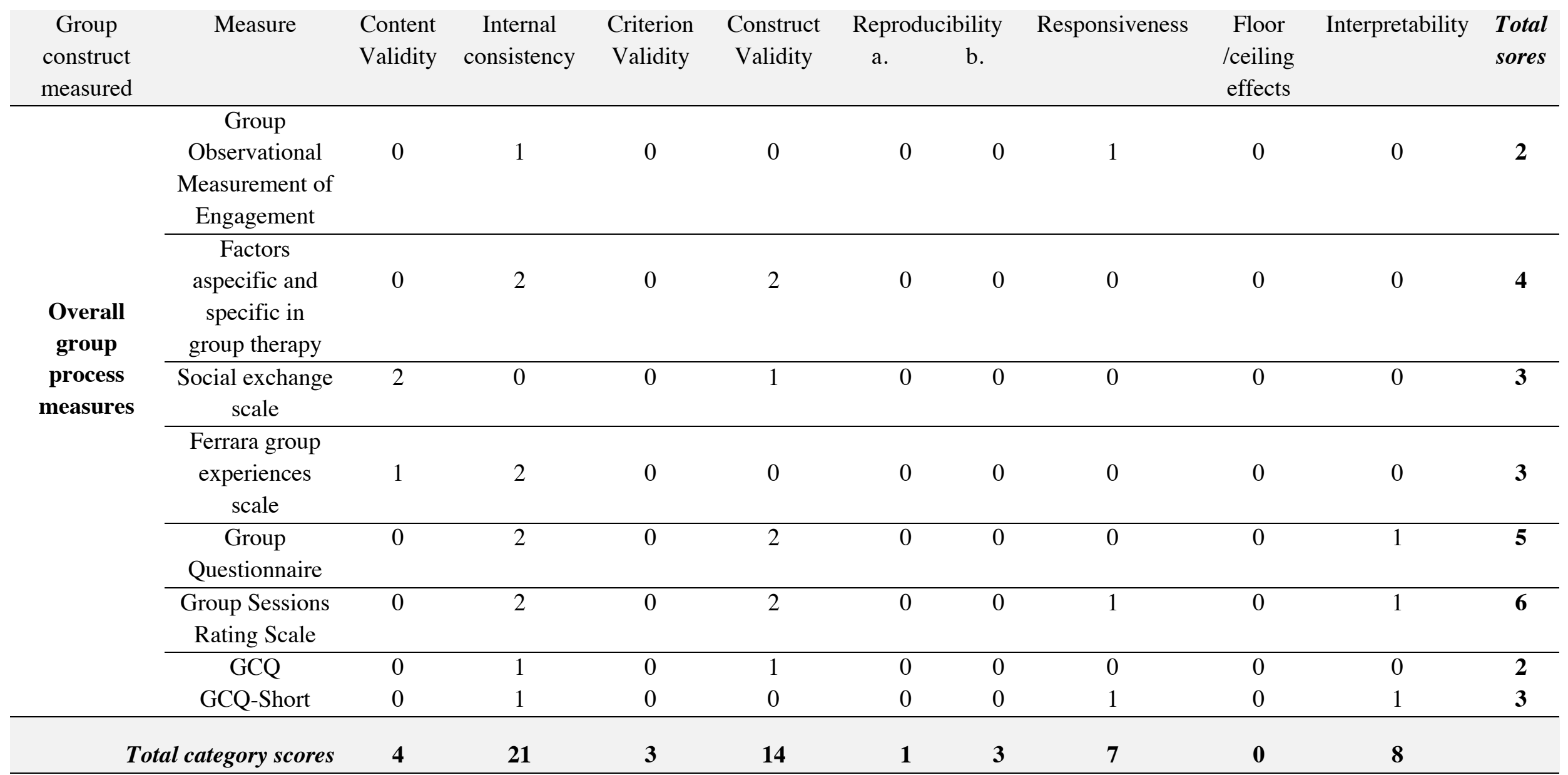

NB: $a=$ Responsiveness Agreement $b=$ Responsiveness Reliability; TFI = Therapeutic Factor Inventory; GCQ = Group Climate Questionnaire 


\section{Supplementary Material}

Table 1: Search terms included in the literature review
Measure
Group therapeutic process
Group therapy

$\begin{array}{lll}\text { Measure } & \text { Group climate } & \text { Group therapy } \\ \text { Instrument } & \text { Cohesion } & \text { Group psychotherapy } \\ \text { Questionnaire } & \text { Alliance } & \text { Group cognitive behavioural } \\ \text { Scale } & \text { Empathy } & \text { therapy } \\ \text { Assessment } & \text { Therapeutic relationship } & \text { Dynamic groups } \\ \text { Reliability } & \text { Therapeutic factors } & \text { Group analytic therapy } \\ \text { Validity } & \text { Engagement } & \text { Psychoanalytic therapy } \\ \text { Psychometric } & \text { Curative climate } & \text { Tavistock groups } \\ \text { Patient health } & \text { Social interaction } & \text { Interpersonal group therapy } \\ \text { Questionnaire/ or } & \text { Interpersonal relationships } & \text { Group analysis } \\ \text { psychometrics/ } & \text { Synchrony } & \text { Psychodynamic Psychotherapy } \\ & \text { Motion analysis } & \text { Counselling groups } \\ & \text { Nonverbal behaviour } & \text { Group counselling } \\ & \text { Gestures behaviours } & \text { Support groups } \\ & \text { Interpersonal } & \text { Couples therapy } \\ & \text { Group process } & \text { Family therapy } \\ & \text { Group experience } & \text { Marital therapy }\end{array}$


Table 2: Terwee and colleagues' (2007) criteria guidance on assessing development procedures

\begin{tabular}{|c|c|c|c|}
\hline Property & Definition & & Quality Criteria (Score / Definition) \\
\hline \multirow[t]{3}{*}{$\begin{array}{l}\text { Content } \\
\text { validity }\end{array}$} & \multirow{3}{*}{$\begin{array}{l}\text { Extent to which concepts of } \\
\text { interest are comprehensively } \\
\text { represented by items in the } \\
\text { questionnaire. }\end{array}$} & 2 & $\begin{array}{l}\text { Clear description of a) measurement aim of the questionnaire; b) target population; c) } \\
\text { concepts intended to measure; d) item selection and e) target population AND } \\
\text { (investigators OR experts) involved in item selection; f) clear interpretability of the items. }\end{array}$ \\
\hline & & 1 & $\begin{array}{l}\text { A clear description of above-mentioned aspects is lacking OR only target population } \\
\text { involved OR doubtful design or method }\end{array}$ \\
\hline & & 0 & No target population involvement OR no information found on target population. \\
\hline \multirow[t]{3}{*}{$\begin{array}{l}\text { Internal } \\
\text { consistency }\end{array}$} & \multirow{3}{*}{$\begin{array}{l}\text { Assessment of whether items in } \\
\text { scale of questionnaire are inter- } \\
\text { correlated, i.e. are measuring } \\
\text { the same construct }\end{array}$} & 2 & $\begin{array}{l}\text { Factor analyses performed on adequate sample size }(7 * \# \text { items and } \geq 100) \\
\text { AND Cronbach's alpha(s) calculated per dimension AND Cronbach's alpha(s) between } \\
0.70 \text { and } 0.95 \text {. }\end{array}$ \\
\hline & & 1 & $\begin{array}{l}\text { No factor analysis OR doubtful design or method OR Cronbach's alpha(s) }<0.70 \text { or }>0.95 \text {, } \\
\text { despite adequate design and method. }\end{array}$ \\
\hline & & 0 & No information found on internal consistency. \\
\hline \multirow{3}{*}{$\begin{array}{l}\text { Criterion } \\
\text { validity }\end{array}$} & \multirow{3}{*}{$\begin{array}{l}\text { The extent to which scores on a } \\
\text { particular questionnaire relate } \\
\text { to a gold standard }\end{array}$} & 2 & Convincing arguments gold standard is "gold" AND correlation with gold standard $\geq 0.70$ \\
\hline & & 1 & No convincing arguments that gold standard is "gold" OR doubtful design or method. \\
\hline & & 0 & $\begin{array}{l}\text { Correlation with gold standard }<0.70, \text { despite adequate design and method OR no } \\
\text { information found on criterion validity. }\end{array}$ \\
\hline \multirow[t]{3}{*}{$\begin{array}{l}\text { Construct } \\
\text { validity }\end{array}$} & \multirow{3}{*}{$\begin{array}{l}\text { The extent to which scores on a } \\
\text { particular questionnaire relate } \\
\text { to other measures in a manner } \\
\text { that is consistent with } \\
\text { theoretically derived } \\
\text { hypotheses }\end{array}$} & 2 & $\begin{array}{l}\text { Specific hypotheses were formulated AND at least } 75 \% \text { of the results are in accordance } \\
\text { with these hypotheses. }\end{array}$ \\
\hline & & 1 & Doubtful design or method (e.g., no hypotheses) \\
\hline & & 0 & $\begin{array}{l}\text { Less than } 75 \% \text { of hypotheses were confirmed, despite adequate design and methods OR no } \\
\text { information found on construct validity }\end{array}$ \\
\hline
\end{tabular}


Table 1. continued.

$$
\text { Property }
$$

Reproducibility The extent to which the scores

(Agreement) on repeated measures are close to each other (absolute measurement error)
Quality Criteria (Score / Definition)

2 MIC<SDC OR MIC outside the LOA OR convincing arguments agreement is acceptable;

1 Doubtful design or method OR (MIC not defined AND no convincing arguments that agreement is acceptable)

$0 \quad$ MIC $\geq$ SDC OR MIC equals or inside LOA, despite adequate design and method OR no information found on agreement.

2 ICC or weighted Kapp $\geq 0.70$

Reproducibility The extent patients can be

(Reliability) distinguished from each other, despite measurement errors (relative measurement error)

1 Doubtful design or method (e.g., time interval not mentioned)

$0 \quad$ ICC or weighted Kappa $<0.70$, despite adequate design and method; OR No information found on reliability.

\begin{tabular}{ll}
\hline Responsiveness & The ability of a questionnaire \\
& to detect clinically important \\
& changes over time
\end{tabular}

Floor and The number of respondents ceiling effects who achieved the lowest or highest possible score

Interpretability The degree to which one can assign qualitative meaning to quantitative scores

2 SDC or SDC $<$ MIC OR MIC outside the LOA OR RRO1.96 OR AUC $\geq 0.70$;

1 Doubtful design or method;

0 SDC or SDC $\geq$ MIC OR MIC equals or inside LOA OR RR $\leq 1.96$ OR AUC $<0.70$, despite adequate design and methods; OR No information found on responsiveness.

$2 \leq 15 \%$ of the respondents achieved the highest or lowest possible scores;

1 Doubtful design or method;

$0>15 \%$ of the respondents achieved the highest or lowest possible scores, despite adequate design and methods OR No information found on interpretation.

2 Mean/SD scores presented of at least four relevant subgroups of patients and MIC defined;

1 Doubtful design or method OR less than four subgroups OR no MIC defined.

0 No information found on interpretation

NB: MIC=minimal important change; SDC=smallest detectable change; LOA=limits of agreement $; C C=$ Intraclass correlation; SD=standard deviation Doubtful design or method = lacking of a clear description of the design or methods of the study, sample size smaller than 50 subjects (should be at least 50 in every (subgroup) analysis), or any important methodological weakness in the design or execution of the study 